\title{
The importance of communication in pediatric oncology palliative care: focus on Humanistic Nursing Theory
}

\author{
Jael Rúbia Figueiredo de Sá França ${ }^{1}$ \\ Solange Fátima Geraldo da Costa ${ }^{2}$ \\ Maria Emilia Limeira Lopes ${ }^{3}$ \\ Maria Miriam Lima da Nóbrega ${ }^{2}$ \\ Inacia Sátiro Xavier de França ${ }^{4}$
}

\begin{abstract}
Objective: to investigate and analyze communication in palliative care contexts from the perspective of nurses, based on Humanistic Nursing Theory. Method: this is a field study with a qualitative approach, in which ten nurses working in the pediatric oncology unit of a Brazilian public hospital participated. Semi-structured interviews were used to collect data. The testimonies were qualitatively analyzed using Humanistic Nursing Theory and based on the five phases of Nursing Phenomenology. Results: two thematic categories emerged from the analysis of the study's empirical material: "strategy to humanize nursing care, with an emphasis on relieving the child's suffering" and "strategy to strengthen ties of trust established between nurse and child." Conclusion: communication is an efficacious element in the care provided to the child with cancer and is extremely important to promoting palliative care when it is based on Humanistic Nursing Theory.
\end{abstract}

Descriptors: Nursing; Palliative Care; Communication; Neoplasms; Child.

\footnotetext{
1 Doctoral student, Universidade Federal da Paraíba, João Pessoa, PB, Brazil. Scholarship holder from Coordenação de Aperfeiçoamento de Pessoal de Nível Superior (CAPES).

2 PhD, Associate Professor, Centro de Ciências da Saúde, Universidade Federal da Paraíba, João Pessoa, PB, Brazil.

${ }^{3}$ PhD, Adjunct Professor, Centro de Ciências da Saúde, Universidade Federal da Paraíba, João Pessoa, PB, Brazil.

${ }^{4}$ PhD, Professor, Faculdade de Enfermagem, Universidade Estadual da Paraíba, Campina Grande, PB, Brazil.
} 


\section{Introduction}

Palliative care refers to a differentiated care approach intended to improve the quality of life of patients with advanced stage disease with no possibility of cure, and the quality of life of family members, through appropriate assessment and the treatment of pain and symptoms. Such care is composed of psychosocial and spiritual support(1). This support, however, is not fully developed and for this reason, its strategies of action, such as communication, still represent a real challenge for the health staff, especially for the Nursing staff, whose professionals remain fulltime beside the patients' beds $^{(2)}$.

In the Nursing field, communication is an extremely important tool in the provision of palliative care to patients with no possibility of cure, especially when the patient is a child with cancer. In this context, when a child becomes sick with cancer s/he has to change habits, is subject to restrictions, isolation, has to abandon routine activities, and face recurrent hospitalizations that cause intense suffering ${ }^{(3)}$.

Efficient communication is considered essential to providing integral and humanized care because through it, one can empathically recognize and embrace the patient's needs (especially those of a child with cancer). When nurses use this tool, either verbally or nonverbally, they enable patients to participate in decisionmaking and in specific care related to the disease, aiming for dignified treatment( ${ }^{(4)}$. A study conducted in Sydney, Australia, reports that efficient communication is vital in nursing care. When it is supported by a relationship characterized by feelings, attitude, cooperation and sensitivity, such a tool helps to boost the relationship between the nurse and the child with cancer ${ }^{(4)}$.

From this perspective, communication within palliative care goes far beyond words and content, because in order for it to result in care based on humanization, it has to comprise attentive listening, eye contact, and attitude. The appropriate use of this resource is a proven, efficacious therapeutic measure to be provided to patients who require $i^{(1)}$. In this type of communication, there is relationship and the exchange of ideas and knowledge that generate a new awareness capable of producing changes in the human being and the world(2). For that, communication has to be based on Humanistic Nursing.

Humanistic Nursing is considered a live dialogue that involves an encounter, in which there is an expectation that someone will provide care and someone will receive care; presence, the quality of being receptive and behaving reciprocally toward another; relationship, through which one goes in the direction of another, which promotes an authentic presence; and a call and an answer, which are presented both verbally and nonverbally ${ }^{(5)}$.

In order to use the theoretical framework of Humanistic Nursing, one must rely on the meanings of the methodology of Nursing Phenomenology, which emanate from the dialogical interaction of experiences articulated and shared by nurse researchers who abstract and conceptualize, enabling the investigation of the event Nursing itself through the development of the dialogical process ${ }^{(5)}$. Through this dialogical process, nurses experience the phenomenon Nursing and study how it occurs in real life, embedded in the human context. Therefore, Humanistic Nursing is dialogical in its theoretical and practical aspects, and the meaning of Nursing consists of an inter-subjective existential act.

The methodology of Nursing Phenomenology can be applied in care, teaching, and in Nursing and be developed in five phases(5), which are explained in this study's methodology section.

Hence, the palliative nursing care provided to children with cancer guided by Humanistic Theory, seeks to preserve the patient's physical, moral, emotional and spiritual integrity through objective and flexible care that values distinct worlds: the inner world (I) and outer world (YOU), where the YOU is present. Both describe the special characteristics of a relationship established with another: the relationships of I-YOU (subjectsubject), I-THIS (subject-object) and I-US (subjectcommunity) $)^{(5)}$.

The I-THIS relationship is expressed as a reflection of the individual concerning his/her previous I-YOU relationships. When one reflects upon these relationships, one values objects to be known - the THIS. The I-US relationship enables individuals to acquire their identity through their relational situation, relieve symptoms and promote the personal growth of patients, families and that of the nurses themselves ${ }^{(6)}$.

Despite the importance of communication for palliative care, the Brazilian literature, especially in the Nursing field, reveals there are few studies addressing the process of communication with patients without the prognosis of a cure ${ }^{(6)}$. This fact stresses the relevance of new studies that are able to contribute to the socialization of knowledge concerning the importance of communication in promoting palliative care to children with cancer, based on Nursing theories. 
In this context, this study contributes to filling an existing gap of knowledge concerning the importance of communication within palliative care in pediatric oncology. For that, the following question guided this study: What is the importance of communication in palliative care provided in pediatric oncology from the perspective of nurses?

In accordance with the previous discussion, this study investigates and analyzes communication in palliative care in pediatric oncology from the viewpoint of nurses, based on Humanistic Nursing Theory.

\section{Method}

This is a field study of a qualitative nature, based on the theoretical framework of palliative care and Humanistic Nursing Theory. The study's setting was the Pediatric Unit of a public hospital located in João Pessoa, Brazil. This hospital is a reference unit in this state for the treatment of cancer for children and adolescents, aged from zero to 19 years old, and for adults.

Ten RNs participated in the study. The following inclusion criteria were used: having worked for at least one year in this unit, being active during the data collection period, and being available to participate in the study. Data were collected from April to June 2010 and was only initiated after the Institutional Review Board at the Federal University of Paraíba approved the project (Process No. 062/10). It complied with ethical guidelines that regulate research with human subjects.

With regard to data collection, the empirical material was obtained through semi-structured interviews using a recording system, with questions relevant to the proposed objective: What do you think of communication as an instrument to assist children with cancer who are in the terminal phase? How do you use communication to assist children with cancer in the terminal phase? This stage was only implemented after the participants signed free and informed consent forms. The nurses were contacted at the hospital and the interviews were held on its premises at a place and time suitable for the professionals.

It is worth noting that in order to preserve the anonymity of the nurses participating in the study, the testimonies that resulted from the interviews were identified by the letter " $N$ ", followed by numbers one to 10. Example: the first nurse interviewed was coded as "N1"; the second professional as "N2" and so on.

Empirical data resulting from the interviews were qualitatively systematized according to the $4^{\text {th }}$ phase of Nursing Phenomenology and then categorized. The following categories emerged from the analysis: "strategy to humanize nursing care, with an emphasis on relieving the child's suffering" and "strategy to strengthen ties of trust established between nurse and child."

The content expressed in these categories was qualitatively analyzed according to Humanistic Nursing Theory and based on the five phases of Phenomenological Nursing(5) (applied to the description of the experienced dialogue, existentially, between the researcher and nurses participating in the study), explained as follow:

- Researcher's preparation to know herself - the researcher sought to reflect upon her way of being and acting, integrating the universe of her experiences and subjectivity through literary works, knowledge of movies that addressed the essence of the human being and diverse ways to perceive the world and relate with it.

- The researcher intuitively knows the other person once the researcher was inserted into the study's field, she dedicated herself to a self-knowledge process based on the I-YOU relationship with the nurses in the Pediatric Unit. When reflecting upon her practice, she attempted to remain aware of her own conceptions, and at the same time, be open to others' points of view, listening to the nurses talking about various topics from their own routine related to the nursing care practice, themselves and their families.

- The researcher scientifically knows the other person - The interview technique was used in this phase of Phenomenological Nursing through a semi-structured script with questions that enabled addressing the studied phenomenon.

- The researcher complementarily synthesizes the realities that became known - In this stage, each testimony was read in detail, though without the intention to understand and interpret content, but to opportunely identify its essence. After this phase of avoiding understanding, the researcher successively read the transcribed reports many times, using detailed and individual observations, and coded each report with the purpose to interpret, categorize, and add knowledge obtained through experiences from the previous stages, comparing similarities and differences, and finally synthesize them to grasp the phenomenon more broadly. - Succession from the multiple to the paradoxical unit as the nurse's internal process - the researcher expanded her own point of view, aware of the multiple realities presented, considering their relationships through reflection and analysis, to better understand the studied phenomenon, based on specific literature. 


\section{Results and discussion}

Having this study's objectives as our guide, we sought to attentively investigate and analyze communication as the strategy used by nurses to humanize nursing care based on palliative care and supported by Humanistic Nursing Theory through care actions.

\section{Strategy to humanize nursing care with an emphasis on relieving the child's suffering}

Within this category, the interviewees refer to the importance of human relationships, showing that both verbal and non-verbal communication established with the child experiencing the process of terminal illness, is considered to be the basis of a good interpersonal relationship, intended to enable being-better, as the following testimonies show:

Communication is very important in palliative care. [...] Children, sometimes, during the initial phase of the disease, do not communicate with words, but communicate with their gaze, with touch. You have to understand that! It is a call that the child is presenting to us. [...], Communication is not only with words: it's a gesture, it's eye contact, it's a way of waking up, it's a good day s/he gives you. It's a smile she transmits you; it is knowing how to recognize these signs (N1).

In communication with children, we have to pay attention to all the communication channels (verbal and non-verbal). So, we need to learn to read the children's sixth sense. [...]. In this sense, if she is in the terminal phase, she realizes it's changing, permits other things. [...]. If you get there with a serious look on your face, she already knows something that will cause suffering is coming; you have to transmit joy (E2).

If the child is conscious, I say: be calm, everything will be OK, try to relax, breath normally, stay quiet, try to sleep [...]. So the communication act has to be directed to all the senses (E3).

We try to have a general view: how she is doing and also try to know what she is feeling, communicating (E4).

When you have a child who is in the terminal phase and you give your support through communication [...], you reassure the child, [...]. It's gratifying; it's necessary correct communication, whether it is verbal or non-verbal communication. So, you leave with peace of mind, that you did your job well; and you're not scared of whatever comes to you, in the face of things that you do (E5).

In the face of these testimonies, the communication between nurses and children with cancer is perceived as an authentic presence, available to be with another, to understand and help others. Consequently, it is essential that nurses establish an honest and open relationship with the child to understand his/her experience and develop care to its full potential, based on palliative care, on the demonstration of affection, attention and sensitivity to truly be with another, and to reassure another through verbal and nonverbal communication.

A study conducted in Australia(7) from 2003 to 2005 with 24 parents of children who had died from cancer revealed that the parents correlated palliative care, communication and honest relationships among professionals, parents and children, with the children being comfortable. Nurses stood out as the professionals who were the closest, established the strongest bonds, and were best able to meet the needs of the child/family dyad.

Canadian researchers investigated the opinions of the parents of children receiving palliative care regarding their perspectives concerning professional support for decision-making and collected expressive testimonies reporting the support they received, and the relevance of honest communication and holistic care(8). Another study performed in 22 oncological centers in the United Kingdom, in which 185 children and 126 families participated, reported results indicating the importance of palliative care and teamwork to the process of dying ${ }^{(9)}$.

The literature clarifies that in the act of care (verbal, non-verbal or both), silent eye contact or physical presence, suggests there is a certain degree of inter-subjectivity that ensures the recipient of care acknowledges it. For nurses to be more aware and be able to explore care in its full potential, it is imperative that they seek to focus on ways to be empathetic to the participants'situations ${ }^{(3)}$.

Verbally or non-verbally participating in care, or even participating in both ways, depends on the openness established among the people involved, so that it allows one to become closer in terms of an existential relationship, and those involved present their own uniqueness ${ }^{(3)}$. Therefore, it is essential for nurses to have the ability and sensitivity, in the face of their own actions, to develop interactive care, establishing a relationship based on a true encounter with children who experience the process of finitude, in which the intentionality to act and knowledge that what is expected from each professional in the care process is manifested(10).

\section{Strategy to strengthen ties of trust established between nurse and child}

Communication is a process of involvement that is established, among other ways, through a dialogue 
between people. It is an active process, of attention and active listening. This aspect is referred to by nurses and refers to the establishment of bonds with a child, as expressed below:

This communication issue, I always try to, like, reassure, especially in relation to pain. I try to talk to her, to address her [...] you look into that child's eyes, she is looking at you, she'll trust you. [...], it is a touch, a gaze; you have to show confidence (E6).

When I communicate with a child, I try to become as close as possible, because we know that children are afraid, when they see us wearing white, they don't want to talk. [...]. So, when you reassure the child a little, play, and step out of your routine for a while, you have some time. [...]. Correct communication is when the child (who is already fragile due to the disease) trusts you in the development of the care relationship. So, you have to know what you're going to say. (E7).

Verbal and nonverbal communication is very important because, in the face of a terminal patient, you cannot, visually show what you're feeling, because he knows [...]. We cannot ever go there showing suffering in our eyes. No matter what her condition, sometimes, is pre-coma, $[\ldots]$, she doesn't talk, but sees and listens (E8).

These testimonies show that authentic communication in this interactive process of providing care encourages the child to express thoughts, feelings, and expectations. It establishes a relationship of trust, since nurse and child mutually expose themselves and make a commitment in a constant back and forth movement in the development of care.

Communication as a vehicle to establish a relationship of trust, when nurses provide care to patients (encompassing his/her wholeness), they meet the patients' needs and enable patients to be strengthened in the face of losses, disease, incapacity and death. Strengthening accrues from care, promotion of comfort, relief from pain, and preservation of the patients' and their parents' self-esteem ${ }^{(11)}$.

This assumption was investigated in the Netherlands through a survey, in which 54 parents of children cared for by Nijmegen Medical Center participated. The researchers concluded that the children and their parents presented physical and psychological needs during the phase of palliative care and recommended that professionals pay greater attention to such needs from the perspective of integral care ${ }^{(12)}$.

The testimony of N6 emphasizes how she communicates with children and illustrates such a fact with the situation experienced by one of them with pain. It is clear that the nurse's concern is always to first address the child, no matter how many times it is necessary, because children are able to express what they are feeling. N6's testimony shows that communication is a way to establish bonds with the child so that care acquires a significant dimension through the exchange and sharing of emotions and feelings.

The literature shows that the symptom most evidenced in pediatric oncology is pain. Health professionals, however, pay little attention to effective actions that help children to deal with pain(13).

In the face of such a vulnerable situation for children who are terminal patients, the testimony of N7 asserts how important it is to use correct communication, to know what to say at a time so unique for the child, so that $s /$ he acquires trust in the development of care relationship.

The importance of communication, as a strategy to humanize care, also appeared in the N8's report when she stated that one should not show what $s /$ he is really feeling in front of the child, because no matter how severe the child's condition is, s/he will perceive the professional's feelings and behavior.

Thus, care provided by nurses to children with cancer should focus on care to enable wellbeing and being-better, since it will enable these children to bemore. Hence, in Nursing, the encounter enables one to answer the call for help from those in need ${ }^{(5)}$. Therefore, a relationship based on a genuine presence of care is established, which leads to effective communication and the establishment of trust between the nurses and these children, as in palliative care.

In this line of thought, when the nurse establishes a relationship with the patient that is based on trust, s/he favors care-based bonding that grounds the interpersonal relationship, has a feeling of accomplishment and feels realized and satisfied. Moreover, as the nurse gets as close as possible to the child, s/he can reinforce the importance of communication as a strategy to humanize care, respecting one's time and opening a space for interaction, as illustrated in N7's report. Additionally, the establishment of bonds, associated with the child's needs, can be a way to facilitate treatment adherence ${ }^{(8)}$.

According to the Humanistic Nursing methodology grounded in the inter-subjective dialogical relationship, one should find the human potential that enables wellbeing and being-with. Such a methodology is understood as a communicational process between providing care and the receiving care. The nurses acknowledge in their reports that dialogue is essential to establishing bonds and developing the care process 
based on devotion, attention, sensitivity and on feelings such as love, joy and solicitude, thus establishing trust ${ }^{(4)}$.

The highlighted reports provide evidence that bonding is developed within proximity of care and acquires significant aspects due to exchanges and the sharing of emotions and feelings, with the presence of authentic care. This presence is characterized as an encounter mediated by an inter-subjective relationship of calling and answering, which involves the human condition of beings who experience the care relationship in all their experience of life through dialogue. Therefore, when acknowledging such feelings, nurses consider their potential to change themselves, through the establishment of an authentic inter-subjective relationship, in conditions of being-more, which enables professionals to become more humane ${ }^{(4)}$.

The two analyzed categories show that this form of providing care indicates a need to promote a human and holistic practice of care, developed through cuddling, gazes, words and listening, to meet the patient's needs because $s /$ he is considered unique based on the I-YOU relationship, established in this study between nurses and children, through an encounter, that anticipates their call. In this relationship, being-with is present, represented by the openness of nurses to the children's calls. Nurses are willing to take care of them while taking into consideration their specificities, using verbal attention skills (characterized as a dialogic way of Nursing) and also nonverbal skills, considering the patient as a unique being in the interpersonal relationships of care, based on the establishment of trust relationships.

\section{Final Considerations}

Care delivery in Nursing is a process of building mutual relationships among human beings. Communication in this relationship is an axis for its development, thus, it is conceived by the nurses themselves as one of the most relevant instruments in palliative care.

The theoretical framework used in this study enabled achieving the proposed objective, since Humanistic Nursing Theory proposes a relationship of trust in the involvement of care provided to another, which confers a unique meaning to the human being, an advertiser of the condition of being, of permanence and of the degree of one's presence in others. This is in a process of human interaction, which respects the singularity of each in the relationship that involves care.
The evidence of such a fact appeared in the discussion of categories through statements concerning care that is based on the demonstration of affection, attention and sensitivity in order to truly be with another through verbally and nonverbally communicating with children afflicted by cancer and experiencing terminal illness. In this sense, nurses indicated communication to be a therapeutic instrument between them and these children because it helps them to understand the disease and have greater control over the situation experienced.

The results indicate that authentic communication can occur between the nurse and the child, as well as with all those involved in the process of palliative care. It is directly or indirectly configured as an efficient element in the care provided to the child who experiences the process of finitude and is essential to promoting Humanistic Nursing.

This study has some limitations, such as the small number of participants, which hinders the generalization of results. Furthermore, a lack of similar empirical data in the Brazilian nursing field impeded the generated data from being compared with greater depth.

Therefore, future studies are needed to enable new elements to emerge in order to support the increase in knowledge of communication as an essential strategy to endorse the practice of palliative care directed to the child with cancer.

\section{References}

1. Araújo MMT, Silva MJP. A comunicação com o paciente em cuidados paliativos: valorizando a alegria e o otimismo. Rev Esc Enferm. 2007;41(4):668-74.

2. Araújo MMT, Silva MJP. A. Estratégias de comunicação utilizadas por profissionais de saúde na atenção à pacientes sob cuidados paliativos. Rev. Esc. Enferm.USP. 2012:46(3):626-32.

3. Chico CE, Nascimento EC, Castanheira L, Lima RAG. Children and adolescents with cancer: experiences with chemotherapy. Rev. Latino-Am. Enfermagem. 2010;18(5):864-72.

4. Mullan BA, Kothe EJ. Evaluating a nursing communication skills training course: The relationships between self-rated ability, satisfaction, and actual performance. Nurse Education in Practice. 2010;10(6):374-8.

5. Paterson JG, Zderad LT. Enfermería humanística. México: Editorial Limusa; 1979.

6. Trovo MM, Silva MJP. O conhecimento de estratégias de comunicação no atendimento à dimensão emocional 
em cuidados paliativos. Texto contexto - enferm.

[periódico na Internet]. 2012 Mar [citado 2012 Set 16];21(1):121-9. Disponível em: http://www.scielo.br/ scielo.php?script=sci_arttext\&pid=S0104-

7. Monterosso L, Kristjanson LJ. Supportive and palliative care needs of families of children who die from cancer: an Australian study. Palliat Med.2008;22(1):59-69

8. Tomlinson D, Capra M, Gammon J, Volpe J, Barrera $M$, Hinds PS, et al. Parental decision making in pediatric cancer end-of-life care: using focus group methodology as a prephase to seek participant design input. Eur J Oncol Nurs.2006;10(3):198-206.

9. Vickers J, Thompson A, Collins GS, Childs N, Hain R. Place and provision of palliative care for children with progressive cancer: a study by the paediatric oncology nurses'forum/United Kingdom children's cancer study group palliative care working group. J Clin Oncol. 2007;25(28):4472-6.

10. Oliveira ME, Fenili RM, Zampiere MF, Martins CR. Um ensaio sobre a comunicação no cuidado de enfermagem utilizando os sentidos. Enfermería Global [periódico na Internet]. 2006 [citado 2011 out 15]; 8: [7p]. Disponível em : <htt://www..um.es/eglobal/8/pdf/08e02p.df>.

11. Buisan R, Delgado JC. El cuidado del paciente terminal. Anales Sis San Navarra. 2007;30(supl.3):103-12.

12. Theunissen JMJ, Hoogerbrugge PM, Van Achterberg T, Prins JB, Vernooij-Dassen MJFJ, Van Den Ende CHM. Symptoms in the palliative phase of children with cancer. Pediatr Blood Cancer. 2007;49(2):160-5.

13. Merighi MAB, Jesus MC, Santin KR, Oliveira DM. Caring for newborns in the presence of their parents: the experience of nurses in the neonatal intensive care unit. Rev. Latino-Am. Enferm. 2011;19(6):1398-1404. 